OPEN ACCESS

Edited by:

Anna Napoli,

University of Calabria, Italy

Reviewed by:

Angela Amoresano,

Università degli Studi di Napoli

Federico II, Italy

Liping Yang,

Oregon State University, United States

*Correspondence:

Cheng Guo

cheng_guo@zju.edu.cn

Kezhi Jiang

jiangkezhi@hznu.edu.cn

Specialty section:

This article was submitted to Analytical Chemistry,

a section of the journal

Frontiers in Chemistry

Received: 08 August 2021

Accepted: 04 October 2021

Published: 23 November 2021

Citation:

Zhang X, Wang Y, Hu Y, Guo C, Li C and Jiang $K$ (2021) Characterizing Oligomeric Hydroxyl Silicon Oils by MALDI-TOF MS With the Pyridine-

Modified Matrix.

Front. Chem. 9:755174

doi: 10.3389/fchem.2021.755174

\section{Characterizing Oligomeric Hydroxyl Silicon Oils by MALDI-TOF MS With the Pyridine-Modified Matrix}

\author{
Xiaoxiao Zhang ${ }^{1,2}$, Yan Wang ${ }^{1}$, Yiqiu $\mathrm{Hu}^{2}$, Cheng Guo ${ }^{2 *}$, Chenghua $\mathrm{Li}^{1}$ and Kezhi Jiang ${ }^{1 *}$ \\ ${ }^{1}$ College of Material, Chemistry and Chemical Engineering, Key Laboratory of Organosilicon Chemistry and Material Technology \\ of Ministry of Education, Hangzhou Normal University, Hangzhou, China, ${ }^{2}$ Cancer Institute (Key Laboratory of Cancer Prevention \\ and Intervention, China National Ministry of Education), The Second Affiliated Hospital, Zhejiang University School of Medicine, \\ Hangzhou, China
}

Matrix-assisted laser desorption ionization time-of-flight mass spectrometry (MALDI-TOF) is a powerful technique for analysis of various polymers, but it is still very difficult to characterize silicone oil due to its poor ionization efficiency. In this work, oligomeric hydroxyl silicone oils were successfully characterized by MALDI-TOF, by using pyridine-modified 2,5-dihydroxylbenzoic acid (DHB) as the matrix. Furthermore, the mixed crystal of DHB and hydroxyl silicone oil was analyzed by scanning electron microscopy (SEM) and energy disperse spectroscopy (EDS), and the analytical results verified that modification with pyridine could remarkably improve the solubility of hydroxyl silicone oil in DHB, leading to the enhancement of its ionization efficiency in MALDI. The analysis of the MS spectra of a series of hydroxyl silicone oils indicated that they tended to be ionized by the attachment with $\mathrm{Na}^{+}$, and the average molecular weight and the degree of polymerization were measured for several oligomeric hydroxyl silicon oils.

Keywords: silicon oil, MALDI-TOF, crystal structure of matrix, pyridine-modified DHB, ionization efficiency

\section{INTRODUCTION}

Hydroxyl silicone oil refers to a linear polysiloxane with the $\mathrm{Si}-\mathrm{O}-\mathrm{Si}$ bond as the main chain and the silicon hydroxyl as the end group in the structure (Figure 1). It is usually maintained in the liquid state at ambient temperature. Owing to its plentiful merits, such as electric insulation, anti-high and -low temperatures, chemical inertia, physiological inertia, low surface tension, and water-repellent and moisture-resistant performance, silicone oil and its derivative products have been extensively applied to electricity, light industry, construction, and other fields (Chen et al., 2009; Mei et al., 2014; Aziz et al., 2018; Zhang et al., 2020). Currently, infrared (IR) spectroscopy, nuclear magnetic resonance (NMR), gel permeation chromatography (GPC), supercritical fluid chromatography (SFC), and matrix-assisted laser desorption ionization time-of-flight mass spectrometry (MALDI-TOF) are the powerful techniques to characterize silicone oil (Semchyschyn et al., 2000; Chmelik et al., 2001; Ren et al., 2019; Liu et al., 2021). GPC is a popular technique to determine the average molecular weight of polymers, but it is not suitable for the analysis of oligomeric hydroxyl silicone oils (Montaudo et al., 1995). Thus, it is essential to develop an alternative method for the characterization of the average molecular weight of oligomeric hydroxyl silicone oils.

MALDI-TOF has been widely applied for characterizing peptides, proteins, oligomers, and polymers since its invention in the 1980s, due to its high sensitivity and convenient operation (Karas et al., 1988; Tanaka et al., 1988; Li et al., 2019). The MALDI-TOF analysis can provide many 


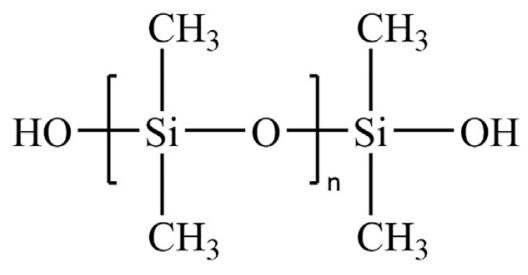

FIGURE 1 | Structure of hydroxyl silicone oil.

important information of polymers, including the repeating unit, the molecular weight distribution, and the end group (Yalcin et al., 1997; Hanton et al., 2000; Pasch et al., 2000; Bauer et al., 2002; Peacock et al., 2004). Thus, it has become an important technique to characterize oligomers or polymers (Scrivens et al., 2000; Chmelik et al., 2001; Hanton, 2001). However, silicone oil belongs to a non-polar polymer, and it is very difficult to be ionized in the MALDI source (Mautjana et al., 2012).

Interestingly, it has been reported that the addition of some organic bases could improve the homogeneous distribution of the analyte in the traditional matrix and increase the dot-to-dot reproducibility in MALDI-TOF analysis (Snovida et al., 2008). In this work, oligomeric hydroxyl silicone oils were characterized by MALDI-TOF with the pyridine-modified 2,5dihydroxylbenzoic acid (DHB) as the matrix, and the corresponding solid crystals were analyzed by scanning electron microscopy (SEM) and energy disperse spectroscopy (EDS) in order to probe the intrinsic mechanism on the improvement of the ionization efficiency originating from the modification of the matrix with pyridine.

\section{EXPERIMENT}

\section{Reagents and Materials}

Hydroxyl silicone oils with different viscosities were purchased from Qingdao Fenghong Chemical Co., Ltd. (Shandong, China). Highperformance liquid chromatography (HPLC)-grade methanol $(\mathrm{MeOH})$ was purchased from Sigma-Aldrich (St. Louis, MO, United States). HPLC-grade tetrahydrofuran (THF) was purchased from Merck Millipore (Billerica, MA, United States). 2,5-Dihydroxylbenzoic acid (DHB) was purchased from Shanghai Macklin Biochemical Co., Ltd. (Shanghai, China). Sodium acetate $(\mathrm{NaAc})$ and pyridine were purchased from Sinopharm (China). The water used in all experiments was prepared in a Milli-Q water purification system with a resistivity $\geq 18.2 \mathrm{M} \Omega \mathrm{cm}^{-1}$.

\section{Instruments}

The microflex MALDI-TOF system was produced by Bruker Corporation (Germany). The BS110S precision balance was produced by Sartorius (Germany). The YM-080S Ultrasonic Cleaner was manufactured by Fang Ao Microelectronics Co., Ltd. (Shenzhen, Guangdong, China). The Sigma 500 scanning electron microscope (SEM) was produced by Zeiss (Germany). The energy disperse spectroscopy (EDS) system was produced by EDAX (United States).

\section{Experimental Procedure}

DHB was weighted and dissolved in THF to prepare a $100 \mathrm{mg} / \mathrm{mL}$ solution. $50 \mu \mathrm{L}$ pyridine solution was added into $1.0 \mathrm{~mL}$ DHB solution to prepare a solution of pyridine-modified DHB. The cationization reagent $(\mathrm{NaAc})$ was weighted and dissolved in $\mathrm{MeOH} / \mathrm{H}_{2} \mathrm{O}(50: 1, \mathrm{~V}: \mathrm{V})$ to prepare a $100 \mathrm{mM}$ solution. Hydroxyl silicone oils were weighted separately and dissolved in THF to prepare a $1 \mathrm{mg} / \mathrm{mL}$ solution. The mixed solution was prepared by mixing the above solutions according to oligomer/ matrix/NaAc (or THF) ratio $(1: 5: 1, \mathrm{~V} / \mathrm{V} / \mathrm{V})$, and the dissolving process was assisted by ultrasound.

In MALDI-TOF experiments, $1.0 \mu \mathrm{L}$ mixed solution was dried on a stainless steel target at room temperature for MALDI-TOF analysis. The operating parameters of MALDI-TOF were as follows: the nitrogen laser wavelength was $337 \mathrm{~nm}$ and the laser pulse width was $3 \mathrm{~ns}$. In the direct radiation mode, the acceleration voltage was $20.0 \mathrm{kV}$ and the reflection voltage was $23.0 \mathrm{kV}$. A single scan of the mass spectrum signal was added up to 100 times.

In SEM and EDS experiments, $10.0 \mu \mathrm{L}$ mixed solution was dropped on a tin foil to dry, and the formed dry point was sprayed with platinum to enhance its electrical conductivity. Then, the dry point was subjected to SEM and EDS analysis. The SEM analysis was carried out at the testing voltage of $3 \mathrm{kV}$ under the vacuum of $5.4 \times 10^{-8} \mathrm{~Pa}$. The EDS analysis was carried out at the testing voltage of $10 \mathrm{kV}$.

\section{RESULTS AND DISCUSSION}

\section{Effect of the Modified Matrix on the Ionization Efficiency}

The $30 \mathrm{cP}$ hydroxyl silicone oil was selected as a model for the MALDI-TOF analysis to investigate the effect of matrix on the ionization efficiency. As shown in Figure 2, the MS showed a series of equidistant peaks and an approximate $t$-distribution in the intensity of the MS signals, indicating a classical MS of the polymer. The mass gap of $74 \mathrm{Da}$ for the neighboring peaks in the MS indicated the signal of silicone oil with the repeating unit of $\left(\mathrm{SiOMe}_{2}\right)$. With the pure DHB as the MALDI matrix (Figure 2A), the intensity of the silicone oil signal was about 600 at $1800 \mathrm{Da}$, while that of the corresponding noise reached 400 , indicating a bad signal-to-noise ratio $(\mathrm{S} / \mathrm{N})$. At the same time, the addition of ionization agent $(\mathrm{NaAc})$ into the $\mathrm{DHB}$ matrix could not significantly improve the ionization efficiency of the hydroxyl silicone oils in the MALDI-TOF MS (Supplementary Figure S1). To be interesting, the corresponding $\mathrm{S} / \mathrm{N}$ increased about two times with the pyridine-modified DHB as the matrix (Figure 2B). What's more exciting, the noise intensity dropped to about 50 , and thus, the corresponding $\mathrm{S} / \mathrm{N}$ increased to 8 with the addition of some NaAc into the pyridine-modified DHB matrix. Thus, the MALDI-TOF MS was competent for structure characterization of hydroxyl silicone oils.

Similar results were obtained for MALDI-TOF analysis of the $50 \mathrm{cP}$ and the $150 \mathrm{cP}$ hydroxyl silicone oils (Supplementary Figures S2 and S3). With modification of the matrix, an enough intensive signal was produced for the MALDI-TOF MS of hydroxyl silicone oils, and thus various structural information could be obtained from the MALDI-TOF analysis. 


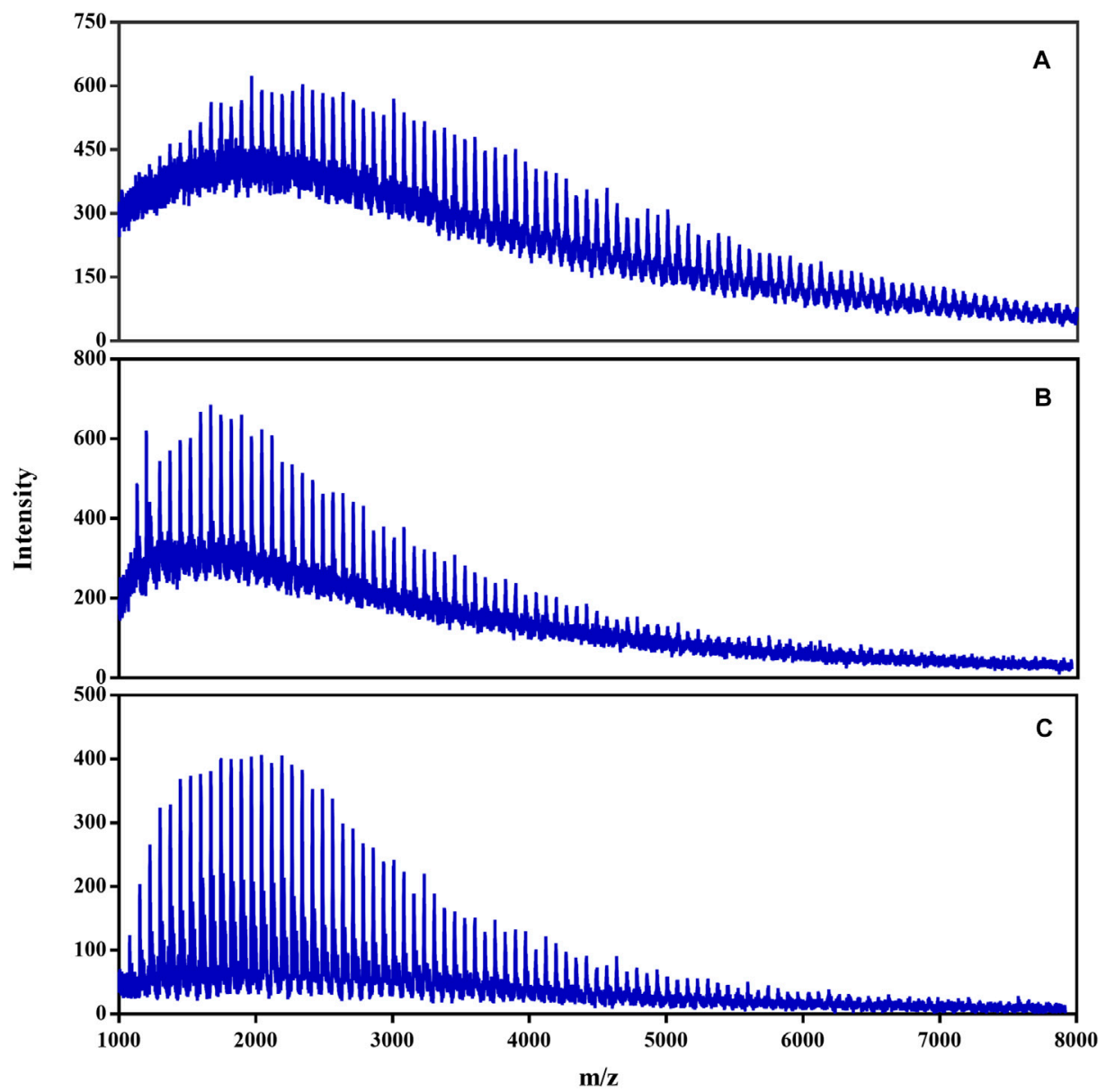

FIGURE 2 | MALDI-TOF MS of $30 \mathrm{cP}$ hydroxyl silicone oil with the different matrix: A) DHB, B) pyridine-modified DHB, C) pyridine-modified DHB with the addition of NaAc.
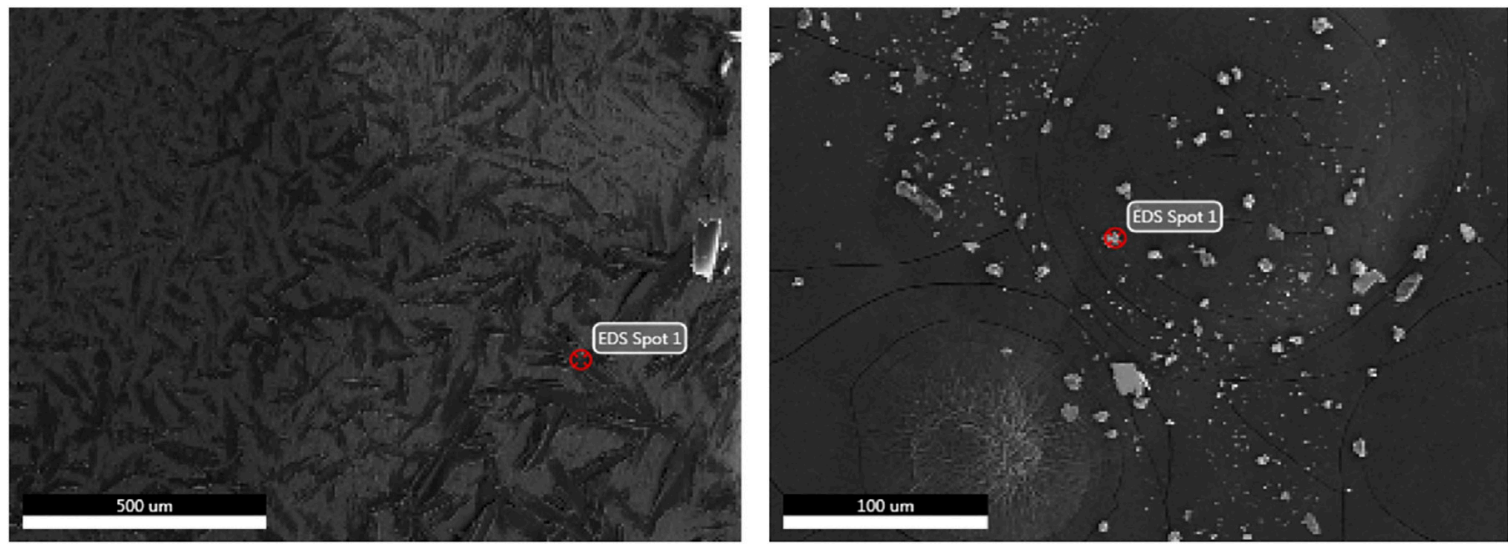

FIGURE 3 | SEM images of the schistose crystal (left) and scattered particles (right) in the mixed crystal of DHB and $30 \mathrm{cP}$ hydroxyl silicone oil.

\section{SEM and EDS Characterizing the Mixed Crystal of Matrix and Analyte}

In order to further investigate the effect of matrix on the ionization efficiency, the mixed crystal of matrix and analyte was characterized by SEM and EDS. Figure 3 shows the SEM of the mixed crystal of $\mathrm{DHB}$ and $30 \mathrm{cP}$ hydroxyl silicone oil, in which there were full of the schistose crystal with the irregular surface and scattered particles with different diameters at the macro-scale level of $100 \mu \mathrm{m}$. EDS 

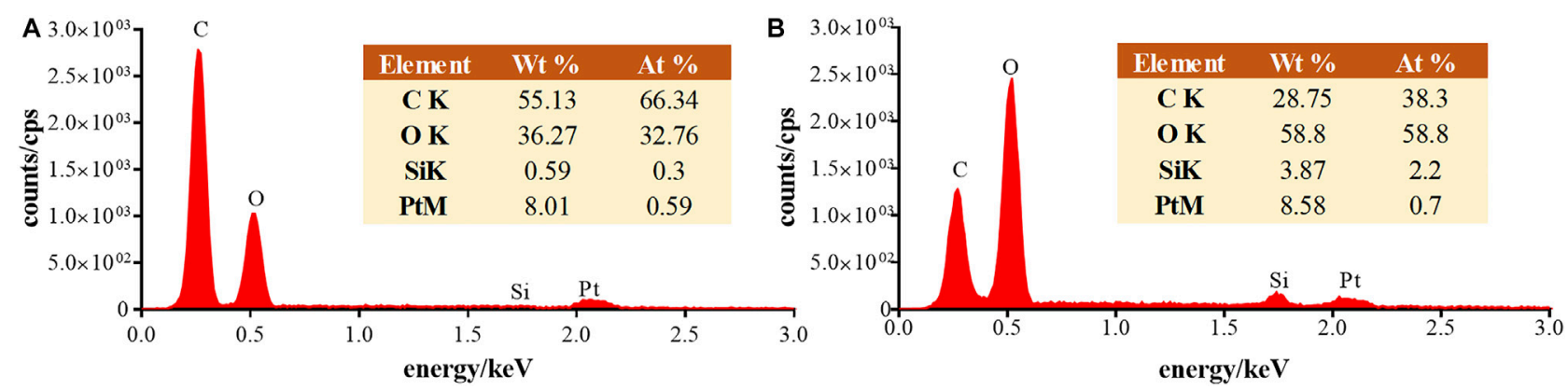

FIGURE 4 | EDS images of the schistose crystal (A) and the particle (B) in mixed crystal of DHB and $30 \mathrm{cP}$ hydroxyl silicone oil.

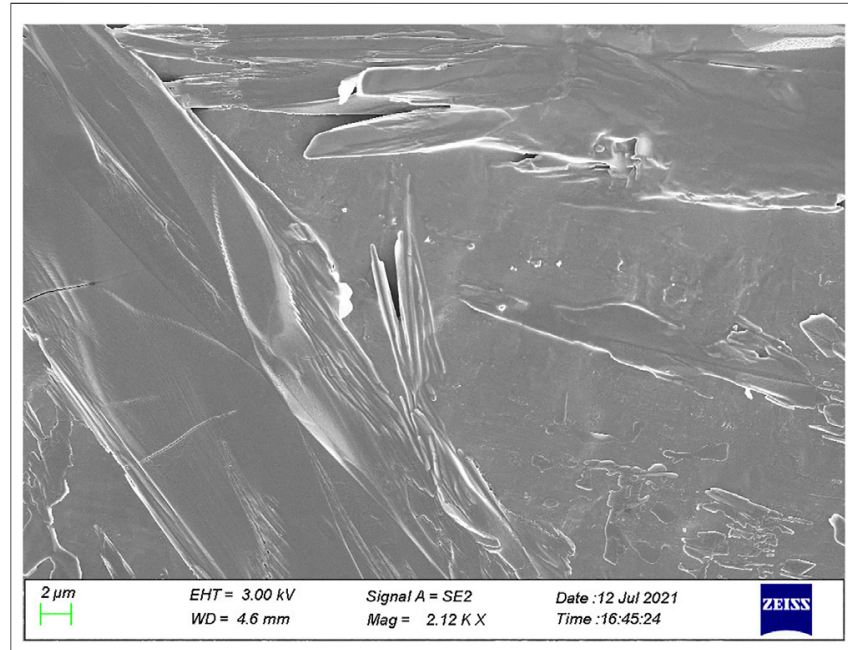

FIGURE 5 | SEM image (at the $2 \mu \mathrm{m}$ level) of the mixed crystal of DHB and $30 \mathrm{cP}$ hydroxyl silicone oil.

analysis of the schistose crystals (Figure 4A) showed the main elements of $\mathrm{C}$ and $\mathrm{O}$, indicating the identity of compound DHB. In contrast, there was significantly more content of both $\mathrm{O}$ and $\mathrm{Si}$ in the EDS of the particle (Figure 4B), which was consistent with the identity of hydroxyl silicone oil. Thereby, the silicone oil was heterogeneously distributed in the DHB matrix.

Further magnification of the mixed crystal at a scale level of $2 \mu \mathrm{m}$ resulted in many irregular tabular crystals with the obvious interface (Figure 5). The corresponding width was found at the $\mu \mathrm{m}$-scale level. Similarly, the addition of NaAc into DHB did not significantly change the shape of the mixed crystal of matrix and analyte (Supplementary Figure S4). The above experimental results indicated that DHB had poor solubility with hydroxyl silicone oil, and thus, poor ionization efficiency was obtained for MALDI-TOF analysis of hydroxyl silicone oil with the pure DHB as the matrix.

On the contrary, mixing DHB with pyridine obviously changed the shape of the mixed crystal of matrix and analyte. As shown in Figure 6, the crystal structure almost disappeared, and the image was filled with kinds of crystal particles. The large particles had the diameters of only $39 \mathrm{~nm}$. In addition, there were

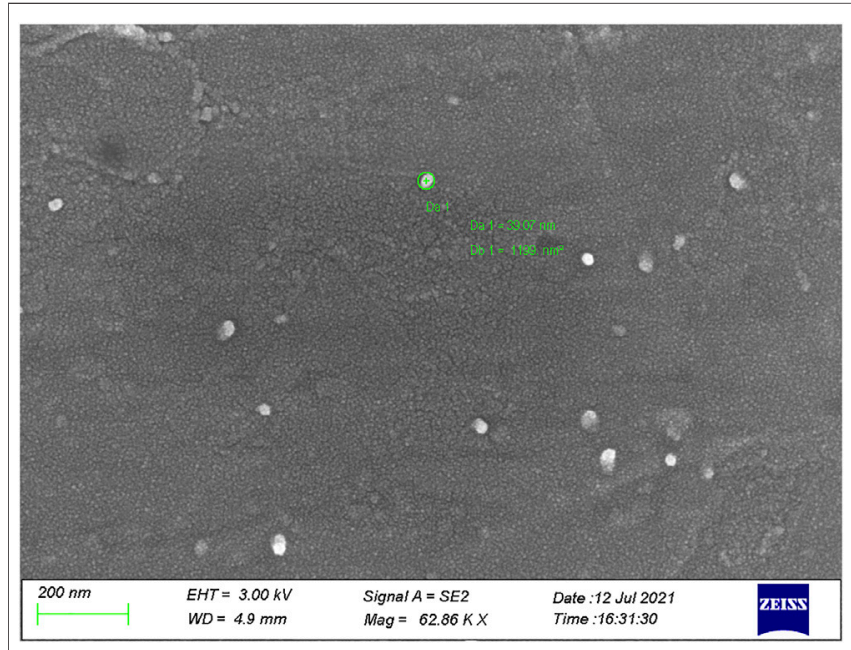

FIGURE 6 | SEM image (at the $200 \mathrm{~nm}$ level) of the mixed crystal of the pyridine-modified DHB and $30 \mathrm{cP}$ hydroxyl silicone oil.

much more particles with the diameters less than $10 \mathrm{~nm}$, which is almost near the size of a molecule. Similarly, the addition of $\mathrm{NaAc}$ also did not obviously change the shape of the mixed crystal of matrix and analyte, in which many scattered crystal particles had diameters of $38 \mathrm{~nm}$ and much more particles showed diameters less than $10 \mathrm{~nm}$ (Supplementary Figure S5). The above experimental results showed that the mixture of hydroxyl silicone oil in the pyridine-modified DHB matrix was more uniform, in which the crystal cluster diameters decreased and the solubility increased obviously. As a result, it is much easier for the matrix to transfer the absorbed laser energy to the analyte in the process of ionization. Thereby, much better ionization efficiency was obtained for hydroxyl silicone oil, when using pyridine-modified DHB as the MALDI-TOF matrix.

\section{Characterization of Oligomeric Hydroxyl Silicone Oils}

According to the optimized experimental parameters, various oligomeric hydroxyl silicone oils were characterized by MALDI- 

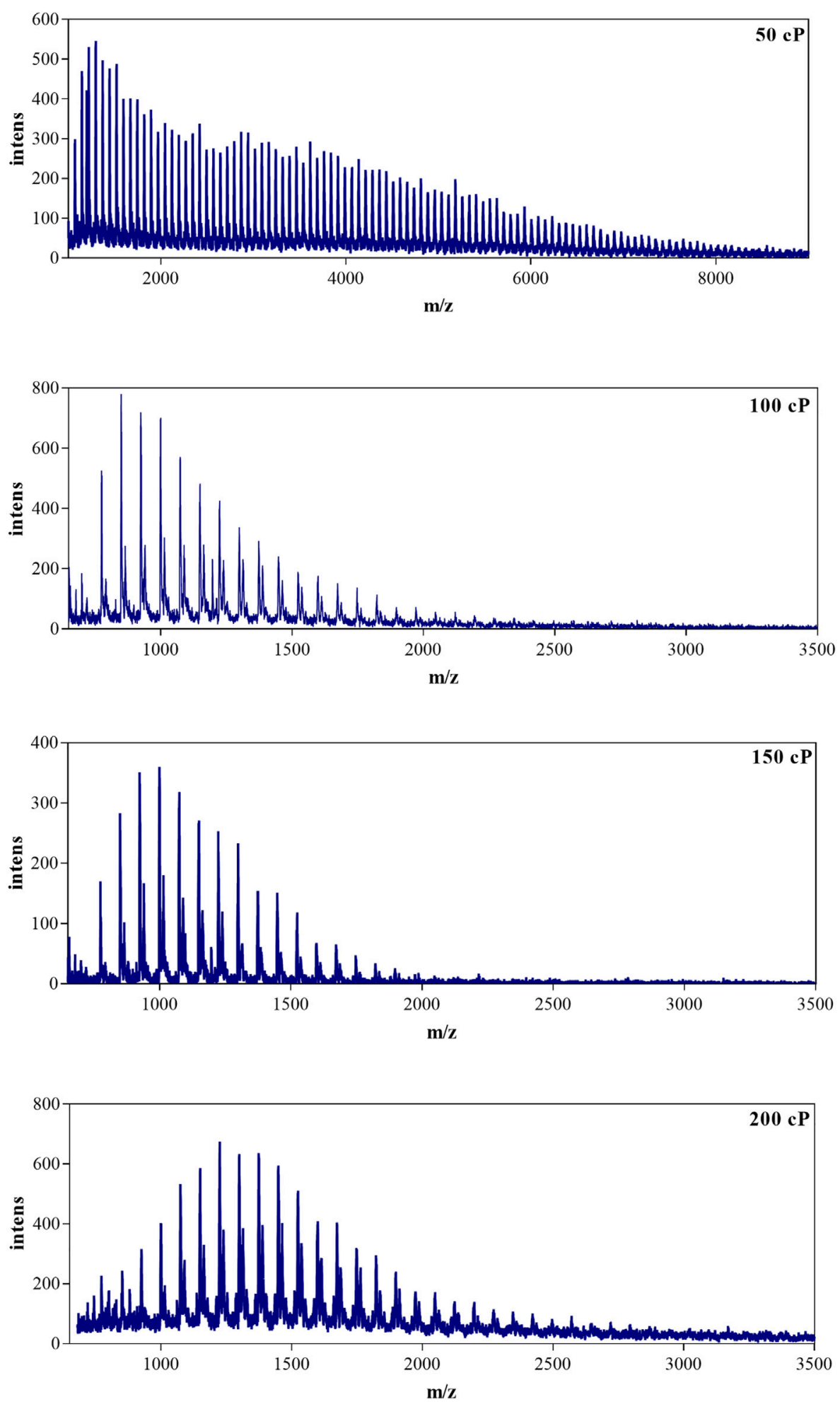

FIGURE 7 | MALDI-TOF MS of hydroxyl silicone oils (50 cP, 100cP, 150cP and $200 \mathrm{cP}$ ) with the matrix of DHB modified by pyridine and NaAc.

TOF (Figure 2C and Figure 7). As can be seen, the $m / z$ ratio of $30 \mathrm{cP}$ hydroxyl silicone oil mainly ranges from 1,000 to 7,000 , and the MS data of the typical $30 \mathrm{cP}$ hydroxyl silicone oil are listed in Table 1. The mass gap (74 Da) of the neighboring peaks in the MS indicates the repeating unit of $\left(\mathrm{SiOMe}_{2}\right)$. The identity of the attached $\mathrm{Na}^{+}$can give a reasonable ascription of all the 
TABLE 1 | MALDI-TOF MS data of $30 \mathrm{cP}$ hydroxyl silicone oil.

\begin{tabular}{|c|c|c|c|c|c|}
\hline$[\mathrm{M}+\mathrm{Na}]^{+}$ & Chemical formula & Intensity & $(\mathrm{M}+\mathrm{Na})^{+}$ & Chemical formula & Intensity \\
\hline$m / z$ & & & $m / z$ & & \\
\hline 1,078 & $\mathrm{C} 28 \mathrm{H} 86015 \mathrm{Si} 14 \mathrm{Na}$ & 124 & 2,710 & $\mathrm{C} 72 \mathrm{H} 218 \mathrm{O} 37 \mathrm{Si} 36 \mathrm{Na}$ & 291 \\
\hline 1,153 & $\mathrm{C} 30 \mathrm{H} 92016 \mathrm{Si} 15 \mathrm{Na}$ & 203 & 2,784 & $\mathrm{C} 74 \mathrm{H} 224 \mathrm{O} 38 \mathrm{Si} 37 \mathrm{Na}$ & 268 \\
\hline 1,227 & C32H98017Si16Na & 266 & 2,858 & $\mathrm{C} 76 \mathrm{H} 230039 \mathrm{Si} 38 \mathrm{Na}$ & 259 \\
\hline 1,301 & $\mathrm{C} 34 \mathrm{H} 104 \mathrm{O} 18 \mathrm{Si} 17 \mathrm{Na}$ & 324 & 2,933 & $\mathrm{C} 78 \mathrm{H} 236 \mathrm{O} 40 \mathrm{Si} 39 \mathrm{Na}$ & 237 \\
\hline 1,375 & $\mathrm{C} 36 \mathrm{H} 110019 \mathrm{Si} 18 \mathrm{Na}$ & 329 & 3,007 & $\mathrm{C} 80 \mathrm{H} 242 \mathrm{O} 41 \mathrm{Si} 40 \mathrm{Na}$ & 242 \\
\hline 1,449 & $\mathrm{C} 38 \mathrm{H} 116 \mathrm{O} 20 \mathrm{Si} 19 \mathrm{Na}$ & 369 & 3,081 & $\mathrm{C} 82 \mathrm{H} 248 \mathrm{O} 42 \mathrm{Si} 41 \mathrm{Na}$ & 221 \\
\hline 1,523 & $\mathrm{C} 4 \mathrm{OH} 122 \mathrm{O} 21 \mathrm{Si} 2 \mathrm{ONa}$ & 374 & 3,155 & $\mathrm{C} 84 \mathrm{H} 254 \mathrm{O} 43 \mathrm{Si} 42 \mathrm{Na}$ & 189 \\
\hline 1,597 & $\mathrm{C} 42 \mathrm{H} 128 \mathrm{O} 22 \mathrm{Si} 21 \mathrm{Na}$ & 377 & 3,229 & $\mathrm{C} 86 \mathrm{H} 260044 \mathrm{Si} 43 \mathrm{Na}$ & 220 \\
\hline 1,671 & $\mathrm{C} 44 \mathrm{H} 134 \mathrm{O} 23 \mathrm{Si} 22 \mathrm{Na}$ & 376 & 3,303 & $\mathrm{C} 88 \mathrm{H} 266 \mathrm{O} 45 \mathrm{Si} 44 \mathrm{Na}$ & 189 \\
\hline 1745 & $\mathrm{C} 46 \mathrm{H} 140 \mathrm{O} 24 \mathrm{Si} 23 \mathrm{Na}$ & 399 & 3,377 & $\mathrm{C} 90 \mathrm{H} 272 \mathrm{O} 46 \mathrm{Si} 45 \mathrm{Na}$ & 167 \\
\hline 1819 & $\mathrm{C} 48 \mathrm{H} 146 \mathrm{O} 25 \mathrm{Si} 24 \mathrm{Na}$ & 400 & 3,451 & $\mathrm{C} 92 \mathrm{H} 278 \mathrm{O} 47 \mathrm{Si} 46 \mathrm{Na}$ & 161 \\
\hline 1894 & $\mathrm{C} 50 \mathrm{H} 152 \mathrm{O} 26 \mathrm{Si} 25 \mathrm{Na}$ & 400 & 3,526 & $\mathrm{C} 94 \mathrm{H} 284 \mathrm{O} 48 \mathrm{Si} 47 \mathrm{Na}$ & 151 \\
\hline 1968 & $\mathrm{C} 52 \mathrm{H} 158 \mathrm{O} 27 \mathrm{Si} 26 \mathrm{Na}$ & 404 & 3,600 & $\mathrm{C} 96 \mathrm{H} 290049 \mathrm{Si} 48 \mathrm{Na}$ & 149 \\
\hline 2043 & $\mathrm{C} 54 \mathrm{H} 164 \mathrm{O} 28 \mathrm{Si} 27 \mathrm{Na}$ & 407 & 3,674 & C98H296O50Si49Na & 129 \\
\hline 2,117 & $\mathrm{C} 56 \mathrm{H} 170029 \mathrm{Si} 28 \mathrm{Na}$ & 394 & 3,748 & $\mathrm{C} 100 \mathrm{H} 302 \mathrm{O} 51 \mathrm{Si} 50 \mathrm{Na}$ & 148 \\
\hline 2,191 & $\mathrm{C} 58 \mathrm{H} 176030 \mathrm{Si} 29 \mathrm{Na}$ & 406 & 3,822 & $\mathrm{C} 102 \mathrm{H} 308052 \mathrm{Si} 51 \mathrm{Na}$ & 129 \\
\hline 2,265 & $\mathrm{C} 60 \mathrm{H} 182 \mathrm{O} 31 \mathrm{Si} 30 \mathrm{Na}$ & 389 & 3,896 & C104H314O53Si52Na & 130 \\
\hline 2,339 & $\mathrm{C} 62 \mathrm{H} 188 \mathrm{O} 32 \mathrm{Si} 31 \mathrm{Na}$ & 383 & 3,970 & C106H320054Si53Na & 130 \\
\hline 2,414 & $\mathrm{C} 64 \mathrm{H} 194 \mathrm{O} 33 \mathrm{Si} 32 \mathrm{Na}$ & 351 & 4,045 & $\mathrm{C} 108 \mathrm{H} 326055 \mathrm{Si} 54 \mathrm{Na}$ & 99 \\
\hline 2,488 & $\mathrm{C} 66 \mathrm{H} 200034 \mathrm{Si} 33 \mathrm{Na}$ & 351 & 4,119 & $\mathrm{C} 110 \mathrm{H} 332 \mathrm{O} 56 \mathrm{Si} 55 \mathrm{Na}$ & 122 \\
\hline 2,562 & $\mathrm{C} 68 \mathrm{H} 206 \mathrm{O} 35 \mathrm{Si} 34 \mathrm{Na}$ & 338 & 4,193 & C112H338057Si56Na & 111 \\
\hline 2,636 & $\mathrm{C} 70 \mathrm{H} 212 \mathrm{O} 36 \mathrm{Si} 35 \mathrm{Na}$ & 299 & 4,267 & $\mathrm{C} 114 \mathrm{H} 344058 \mathrm{Si} 57 \mathrm{Na}$ & 95 \\
\hline
\end{tabular}

TABLE $2 \mid M_{n}, M_{w}$, and $P D$ of silicone oils with different viscosities.

\begin{tabular}{lcccc}
\hline Sample/viscosity & $\boldsymbol{M}_{\boldsymbol{n}}$ & $\boldsymbol{M}_{\boldsymbol{w}}$ & $\boldsymbol{P D}$ & Si-OH\% \\
\hline $30 \mathrm{CP}$ & 2,383 & 2,658 & 1.12 & 1.61 \\
$50 \mathrm{CP}$ & 3,185 & 3,924 & 1.23 & 1.38 \\
$100 \mathrm{cP}$ & 1,135 & 1,215 & 1.07 & 3.19 \\
$150 \mathrm{cP}$ & 1,151 & 1,201 & 1.04 & 2.90 \\
$200 \mathrm{cP}$ & 1,460 & 1,554 & 1.06 & 2.48
\end{tabular}

signal in the MS of the hydroxyl silicone oil, which agrees well with the fact that it tends to be ionized by the attachment with $\mathrm{Na}^{+}$.

Thus, the number-average molecular weight $\left(M_{n}\right)$, weightaverage molecular weight $\left(M_{w}\right)$, dispersity $(P D)$, and hydroxyl content of silicone oils ( $\mathrm{Si}-\mathrm{OH} \%$ ) were calculated to be 2,276, $2,553,1.12$, and 1.68 , respectively, according to the following formula:

$$
\begin{aligned}
& M_{n}=\sum\left(n_{i} \times M_{i}\right) / \sum n_{i}, \\
& M_{w}=\sum\left(n_{i} \times M_{i}^{2}\right) / \sum\left(n_{i} \times M_{i}\right), \\
& P D=M_{w} / M_{n}, \\
& O H \%=\sum\left(\left(n_{i} / \sum n_{i}\right) / \times 34 / M_{i}\right) \times 100 \%,
\end{aligned}
$$

Here, $n_{i}$ and $M_{i}$ refer to the MS intensity and molecular weight of any component $i$ of the oligomer.

$50 \mathrm{cP}$ hydroxyl silicone oil has the same mass gap $(74 \mathrm{Da})$ of the neighboring peaks in the MS, but it shows a different mass distribution with a wider mass range (1,000-9,000 Da). As shown in Table 2, $50 \mathrm{cP}$ hydroxyl silicone oil has a higher molecular weight, more dispersity, and less hydroxyl content.
As displayed in Figure 7, there are two series of peaks in the MS of 100,150, and $200 \mathrm{cP}$ silicone oils. The mass gap for the adjacent peaks is also $74 \mathrm{Da}\left(\mathrm{SiOMe}_{2}\right)$ in each series of MS peaks. The main series of equidistant peaks is $16 \mathrm{Da}$ less in molecular weight than the corresponding minor series of equidistant peaks, indicating that ionization of hydroxyl silicone oil by the attachment with $\mathrm{Na}^{+}$results in the main one in the MALDITOF MS, and attachment with $\mathrm{K}^{+}$results in the minor one. $\mathrm{K}^{+}$ originates from the residue catalyst $(\mathrm{KOH})$ in the polymerization process. Also, the corresponding parameters of their main sequence peaks mass distribution are listed in Table 2.

Similarly, $M_{n}, M_{w}, P D$, and Si-OH\% of several oligomeric hydroxyl silicone oils were also calculated and are summarized in Table 2. As can be seen, the hydroxyl silicone oils of $100 \mathrm{cP}$, $150 \mathrm{cP}$, and $200 \mathrm{cP}$ have relatively higher viscosity than $30 \mathrm{cP}$ and $50 \mathrm{cP}$, but they show much lower molecular weight $(\sim 1,000 \mathrm{Da}$ vs. $\sim 3,000 \mathrm{Da})$. Thus, molecular weight is not the deciding factor for the viscosity of the oligomeric hydroxyl silicone oil. The results indicate that the content of the silicon hydroxyl group, which results in the formation of an intermolecular hydrogen bond, exerts more influences on their viscosity (Table 2 ).

\section{CONCLUSION}

In this work, the hydroxyl silicone oils have been successfully characterized by MALDI-TOF MS. The effects of the addition of pyridine and cationic reagent into matrix on the characterization of silicone oil were investigated. The results showed that the addition of pyridine and NaAc was beneficial to MALDI-TOF 
MS detection of hydroxyl silicone oils. The reduced baseline, the increased $\mathrm{S} / \mathrm{N}$, and a beautiful peak shape were obtained. Furthermore, the mixed crystal of matrix and $30 \mathrm{cP}$ hydroxyl silicone oil was subjected to SEM and EDS analysis, and the results verified that addition with pyridine promotes the homogeneity of the crystal of DHB and silicone oil. Finally, several oligomeric hydroxyl silicone oils were characterized by MALDI-TOF MS, and the corresponding molecular weight and degree of polymerization were calculated, and the results indicated that the content of the silicon hydroxyl group, rather than the molecular weight, exerts obvious influences on their viscosity.

\section{DATA AVAILABILITY STATEMENT}

The original contributions presented in the study are included in the article/Supplementary Materials, further inquiries can be directed to the corresponding author KJ, jiangkezhi@hznu.edu.cn.

\section{ETHICS STATEMENT}

This research was based on characterizing silicon oils by MALDI-TOF MS with the modified matrix. No human or animal blood samples were used, and thus, ethics approval was not required as per institutional and national guidelines.

\section{REFERENCES}

Aziz, T., Fan, H., Khan, F. U., Haroon, M., and Cheng, L. (2018). Modified Silicone Oil Types, Mechanical Properties and Applications. Polym. Bull. 76, 2129-2145. doi:10.1007/s00289-018-2471-2

Bauer, B. J., Byrd, H. C. M., and Guttman, C. M. (2002). Small Angle Neutron Scattering Measurements of Synthetic Polymer Dispersions in Matrix-Assisted Laser Desorption/ionization Matrixes. Rapid Commun. Mass. Spectrom. 16, 1494-1500. doi:10.1002/rcm.737

Chen, X., and Jiao, C. (2009). Synergistic Effects of Hydroxy Silicone Oil on Intumescent Flame Retardant Polypropylene System. Fire Saf. J. 44, 1010-1014. doi:10.1016/j.firesaf.2009.06.008

Chmelík, J., Planeta, J., Řehulka, P., and Chmelík, J. (2001). Determination of Molecular Mass Distribution of Silicone Oils by Supercritical Fluid Chromatography, Matrix-Assisted Laser Desorption Ionization Time-OfFlight Mass Spectrometry and Their Off-Line Combination. J. Mass. Spectrom. 36, 760-770. doi:10.1002/jms.179

Hanton, S. D., and Liu, X. M. (2000). GPC Separation of Polymer Samples for MALDI Analysis. Anal. Chem. 72, 4550-4554. doi:10.1021/ ac000095n

Hanton, S. D. (2001). Mass Spectrometry of Polymers and Polymer Surfaces. Chem. Rev. 101, 527-570. doi:10.1021/cr9901081

Karas, M., and Hillenkamp, F. (1988). Laser Desorption Ionization of Proteins with Molecular Masses Exceeding 10,000 Daltons. Anal. Chem. 60, 2299-2301. doi:10.1021/ac00171a028

Li, Z., Liu, Q., Lu, X., Deng, C., Sun, N., and Yang, X. (2019). Magnetic MetalOrganic Framework Nanocomposites for Enrichment and Direct Detection of Environmental Pollutants by Negative-Ion Matrix-Assisted Laser Desorption/ ionization Time-Of-Flight Mass Spectrometry. Talanta 194, 329-335. doi:10.1016/j.talanta.2018.10.058

Liu, J., Ronk, M., Fujimori, K., Lee, H., and Nashed-Samuel, Y. (2021). Analysis of Silicone Oil in Prefilled Syringes and Biopharmaceutical Drug Products Using High-Performance Liquid Chromatography. AAPS PharmSciTech 22, 75. doi:10.1208/s12249-021-01947-6

\section{AUTHOR CONTRIBUTIONS}

KJ and CG initiated the study, supervised the study, and discussed the results. XZ, YH, and KJ contributed to method development and performed the experiment. $\mathrm{XZ}, \mathrm{CL}$, and YW contributed to data acquisition and performed the analysis. KJ and $\mathrm{YW}$ contributed to analysis and interpretation of the data. XZ and $\mathrm{KJ}$ contributed to the drafting of the manuscript. All the authors have accepted responsibility for the entire content of this submitted manuscript and approved the submission.

\section{FUNDING}

The authors gratefully acknowledge the financial support from the Analysis and Detection Foundation of Science and Technology Department in Zhejiang Province, China (Grant Nos. LGC21B050009 and LGC19B050008).

\section{SUPPLEMENTARY MATERIAL}

The Supplementary Material for this article can be found online at: https://www.frontiersin.org/articles/10.3389/fchem.2021.755174/ full\#supplementary-material

Mautjana, N. A., and Pasch, H. (2012). Matrix-Assisted Laser Desorption Ionization Mass Spectrometry of Synthetic Polymers. Macromol. Symp. 313314, 157-161. doi:10.1002/masy.201250317

Mei, S. F., Gao, Y. X., Deng, Z. S., and Liu, J. (2014). Thermally Conductive and Highly Electrically Resistive Grease through Homogeneously Dispersing Liquid Metal Droplets inside Methyl Silicone Oil. J. Electron. Packaging 136. doi:10.1115/1.4026414

Montaudo, G., Montaudo, M. S., Puglisi, C., and Samperi, F. (1995). Characterization of Polymers by Matrix-Assisted Laser Desorption/ ionization Time-Of-Flight Mass Spectrometry: Molecular Weight Estimates in Samples of Varying Polydispersity. Rapid Commun. Mass. Spectrom. 9, 453-460. doi:10.1002/rcm.1290090514

Pasch, H., and Ghahary, R. (2000). Analysis of Complex Polymers by MALDI-TOF Mass Spectrometry. Macromol. Symp. 152, 267-278. doi:10.1002/15213900(200003)152:1<267:aid-masy267>3.0.co;2-n

Peacock, P. M., and McEwen, C. N. (2004). Mass Spectrometry of Synthetic Polymers. Anal. Chem. 76, 3417-3428. doi:10.1021/ac040064i

Ren, F., Xu, Q., Zhou, Z., Xu, W., and Ma, H. (2019). Synthesis and Characterization of High Heat Resistant Hydroxyl Silicone Oil with Boron and Sulfoxide in Backbone. Silicon 12, 2203-2210. doi:10.1007/s12633-019-00313-3

Scrivens, J. H., and Jackson, A. T. (2000). Characterisation of Synthetic Polymer Systems. Int. J. Mass Spectrom. 200, 261-276. doi:10.1016/s1387-3806(00) 00322-5

Semchyschyn, D. J., and Macdonald, P. M. (2000). Limits of Detection of Polydimethylsiloxane in29Si NMR Spectroscopy. Magn. Reson. Med. 43, 607-610. doi:10.1002/(sici)1522-2594(200004)43:4<607:aid-mrm17>3.0.co; $2-\mathrm{i}$

Snovida, S. I., Rak-Banville, J. M., and Perreault, H. (2008). On the Use of DHB/ aniline and $\mathrm{DHB} / \mathrm{N}, \mathrm{N}$-dimethylaniline Matrices for Improved Detection of Carbohydrates: Automated Identification of Oligosaccharides and Quantitative Analysis of Sialylated Glycans by MALDI-TOF Mass Spectrometry. J. Am. Soc. Mass. Spectrom. 19, 1138-1146. doi:10.1016/ j.jasms.2008.04.033

Tanaka, K., Waki, H., Ido, Y., Akita, S., Yoshida, Y., Yoshida, T., et al. (1988). Protein and Polymer Analyses up Tom/z 100000 by Laser Ionization Time-Of- 
Flight Mass Spectrometry. Rapid Commun. Mass. Spectrom. 2, 151-153. doi: $10.1002 / \mathrm{rcm} .1290020802$

Yalcin, T., Schriemer, D. C., and Li, L. (1997). Matrix-assisted Laser Desorption Ionization Time-Of-Flight Mass Spectrometry for the Analysis of Polydienes. J. Am. Soc. Mass. Spectrom. 8, 1220-1229. doi:10.1016/s1044-0305(97) 00192-x

Zhang, Y., Liu, Z., Liu, Z., and Yao, L. (2020). Mechanical Properties of HighDuctility Cementitious Composites with Methyl Silicone Oil. Mag. Concrete Res. 72, 747-756. doi:10.1680/jmacr.18.00192

Conflict of Interest: The authors declare that the research was conducted in the absence of any commercial or financial relationships that could be construed as a potential conflict of interest.
Publisher's Note: All claims expressed in this article are solely those of the authors and do not necessarily represent those of their affiliated organizations, or those of the publisher, the editors, and the reviewers. Any product that may be evaluated in this article, or claim that may be made by its manufacturer, is not guaranteed or endorsed by the publisher.

Copyright $\odot 2021$ Zhang, Wang, Hu, Guo, Li and Jiang. This is an open-access article distributed under the terms of the Creative Commons Attribution License (CC $B Y)$. The use, distribution or reproduction in other forums is permitted, provided the original author(s) and the copyright owner(s) are credited and that the original publication in this journal is cited, in accordance with accepted academic practice. No use, distribution or reproduction is permitted which does not comply with these terms. 